\title{
ESCLERÓCITOS: PROPOSTA DE UMA NOVA CATEGORIA DE PALINOMORFOS LATO SENSU
}

\author{
SARAH GONÇALVES DUARTE \\ Laboratório de Nanofósseis, CCMN, IGeo, UFRJ, Av. Athos da Silveira Ramos, 274, Cidade Universitária, Ilha do Fundão, \\ 21949-916, Rio de Janeiro, RJ, Brasil. sarahpalino@yahoo.com.br \\ MITSURU ARAI \\ PETROBRAS/CENPES/PDEXP/BPA, Av. Horácio Macedo, 950, Cidade Universitária, Ilha do Fundão, 21941-915, \\ Rio de Janeiro, RJ, Brasil.arai@petrobras.com.br
}

\begin{abstract}
SCLEREIDS: PROPOSAL FOR A NEW CATEGORY OF PALYNOMORPHS LATO SENSU. Palynological analyses of samples from the Upper Cretaceous successions of certain sedimentary basins of southeastern Brazil have revealed the presence of distinctive organic structures attributable to sclereids, which are cells of sclerenchyma (tissue whose principal function is support and protection of vascular plants). In the present study, fossil sclereids have been identified by light microscopy of strew slides prepared for routine palynological analysis. Thirteen basic radially symmetric morphotypes are recognizable, as follows: aculeata, brevis (short, compact), callosa (thickened, callus-like), crenulata, crucis (cross-shaped), elongata, furcata (branched), perforata, rotunda (rounded), simplex (simple, unbranched), spinosa, tenuis (tenuous), and truncata (truncated). All belong to the group of Astrosclereids, which have star-like shapes. Tentatively, the type simplex can be referred to the Gnetophyta and the family Nymphaeaceae; perforata to Loranthaceae; callosa to Magnoliaceae; and furcata to Rutaceae, Oleaceae and Theaceae. These inferred botanical relationships could, in turn, enhance our understanding of the taxonomic composition of the vegetation bordering the studied basins, thus contributing to paleoenvironmental and paleoclimatic interpretations. Moreover, determining the relationship between the astrosclereid morphotypes and the plant organs bearing them could help in the characterization of the terrigenous influx into the basins. The abundance of fossil astrosclereids could also be indicative of paleowildfires. This is implied by the fact that these microfossils are especially abundant in the Santonian strata of the Campos and Santos basins, which incorporate unequivocal evidence of intense conflagration induced by incendiary volcanic activities.
\end{abstract}

Key words: sclereids, astrosclereids, plant anatomy, palynology, Cretaceous, Brazil.

RESUMO - Análises palinológicas realizadas em amostras provenientes do Cretáceo Superior de algumas bacias sedimentares do Sudeste Brasileiro revelaram estruturas atribuíveis a esclerócitos, células do esclerênquima, tecido que confere rigidez, sustentação e proteção às plantas vasculares. No presente trabalho, os esclerócitos fósseis foram identificados ao microscópio óptico nas mesmas lâminas das análises palinológicas de rotina. O trabalho preliminar permitiu a identificação de 13 formas (morfotipos) básicas, todas pertencentes ao grupo de astroesclerócitos com formato de estrela: aculeata (aculeado), brevis (compacto), callosa (caloso), crenulata (crenulado), crucis (cruciforme), elongata (elongado), furcata (ramificado), perforata (perfurado), rotunda (arredondada), simplex (simples), spinosa (espinhoso), tenuis (tênue) e truncata (truncado). Inferiu-se o morfotipo simples às gnetófitas e à família Nymphaeacea, o perfurado à Loranthaceae, o caloso à Magnoliaceae e o ramificado às famílias Rutaceae, Oleaceae e Theaceae. O estabelecimento da relação dos morfotipos com suas respectivas plantas genitoras permitirá inferir quais grupos taxonômicos vegetais estiveram presentes nas áreas emersas adjacentes às bacias na época de sua deposição, possibilitando atribuir-lhes valor paleoambiental e/ou paleoclimático. Além disso, o estabelecimento da relação entre morfologia dos esclerócitos e o órgão vegetal donde provêm os mesmos, permitirá fazer inferências sobre a natureza do aporte terrígeno da bacia. A presença abundante de esclerócitos fósseis é também indicativa da ocorrência de incêndios pretéritos. Esta hipótese decorre do fato de que astroesclerócitos fósseis são especialmente abundantes no Santoniano das bacias de Campos e Santos, onde já foram registradas evidências irrefutáveis de paleoincêndios de grandes proporções.

Palavras-chave: esclereídes, astroesclerócitos, anatomia vegetal, palinologia, Cretáceo, Brasil.

\section{INTRODUÇÃO}

Análises palinológicas, realizadas em amostras da Petrobras provenientes de estratos do Cretáceo de algumas bacias sedimentares do sudeste brasileiro (principalmente as bacias de Campos e Santos), revelaram estruturas orgânicas de forma estrelada, passíveis de serem tratadas como palinomorfos lato sensu (Arai, 2005). Durante anos, elas fo- 
ram denominadas informalmente "Stellatia nigra" pelos palinólogos da Petrobras, sendo incluídas na categoria de Incertae sedis (origem desconhecida). Recentemente, Mendonça et al. (2007) atribuíram essas estruturas a esclereídes, células do tecido vegetal denominado esclerênquima.

A existência de grande variedade em seus tipos morfológicos serviu de estímulo para inventariar e descrever os principais morfotipos encontrados. A expectativa é de que esclereídes fósseis (esclerócitos) venham a ser estudados como palinomorfos lato sensu, servindo igualmente para fornecer dados bioestratigráficos e paleoambientais.

$\mathrm{Na}$ literatura, encontram-se empregados os termos esclereíde ou esclereide (ABL, 1998, p. 306), esclereídeo (cf. Berta Lange de Morretes in Esau, 1974) e esclerócito (Ferreira, 1986, p. 687). Neste trabalho, adotou-se o termo esclereíde, para a célula que se encontra em tecidos da planta vivente, e o esclerócito, exclusivamente para indicar estruturas fósseis individualizadas, atribuíveis a esclereídes ou a células esclereficadas, encontradas em lâminas palinológicas.

No material estudado, palinomorfos stricto sensu (esporos e grãos de pólen) são raros, em função do paleoincêndio regional que destruiu grande parte da matéria orgânica não enriquecida em lignina, fazendo com que predominem nelas esclereídes, tricomas e outros restos de matéria orgânica lenhosa carbonificada. Assim, o presente trabalho tem como finalidade prática a busca de palinomorfos lato sensu utilizáveis ao zoneamento bioestratigráfico. O detalhamento bioestratigráfico do Santoniano da bacia de Santos revestese de importância especial, pois o referido intervalo contém importantes reservatórios de petróleo e gás.

\section{MATERIAL E MÉTODOS}

Os dados de ocorrências de esclerócitos fósseis foram levantados a partir de 2002, concomitantemente às análises palinológicas de rotina do Centro de Pesquisas da Petrobras (CENPES). O material estudado é representado principalmente pelas amostras de calha e de testemunho provenientes dos poços exploratórios das bacias de Campos e Santos (Figura 1), em intervalos cretáceos de profundidade (cota abaixo do nível do mar) entre $3.300 \mathrm{~m}$ e $5.400 \mathrm{~m}$. Foram analisadas ainda duas amostras do afloramento da Fazenda Nossa Senhora de Fátima, localidade-tipo da Formação São Carlos sensu Castro et al. (2002). O método de preparação de amostras é exatamente o utilizado na paleopalinologia tradicional, ou seja, processamento de amostras de rochas sedimentares com as macerações utilizando os ácidos clorídrico, fluorídrico e nítrico, seguido de montagem de lâminas palinológicas que são analisadas ao microscópio óptico biológico (Uesugui, 1979). Para as análises, utilizou-se microscópio óptico de campo claro Zeiss Axio Imager A1, acoplado a câmera digital Zeiss AxioCam MRc. Algumas amostras, excepcionalmente ricas em esclerócitos, foram analisadas também por microscópio eletrônico de varredura (MEV). Para isto, o resíduo palinológico, depois de seco, foi recoberto por uma fina camada de ouro/paládio, em metalizador EMITECH modelo K575X e analisado em MEV (ZEISS, modelo EVO 40), ope- rando a $20 \mathrm{kV}$. Uma parte do resíduo foi montada em lamínula e, sem ser metalizada, foi submetida ao MEV a baixo vácuo (VPSE - Variable Pressure Scanning Electron microscope, $c f$. Gnauck, 2008). Após a obtenção de imagens em MEV, a mesma lamínula foi montada para microscopia óptica, o que permitiu a comparação das imagens obtidas em duas modalidades de microscopia (óptica e eletrônica).

\section{RESULTADOS}

Graças à existência de padrões morfológicos, esclerócitos isolados são passíveis de receberem um tratamento taxonômico artificial, similar àquele aplicado em palinomorfos stricto sensu dispersos em sedimentos e rochas sedimentares. Entre esclerócitos fósseis, os que são mais passíveis de receberem tratamento como palinomorfo lato sensu são as astroesclereídes que, tendo forma de estrela, são conhecidas na literatura também como "stellately branched sclereids" (Rao, 1951; Rao \& Kelkar, 1951) ou "stellate sclereids" (Tucker, 1977). Rao \& Bhupal (1973) propuseram a reabilitação do termo astroesclereíde que fora proposto por Tschirch (1889, in Rao \& Buphal, 1973). No presente trabalho foram identificados 13 morfotipos básicos de esclerócitos (Figura 2), sendo a maioria astroesclerócitos (apenas o morfotipo arredondado pode provir de epidermes e hipodermes esclerificadas).

Esclerócito tipo aculeado. Astroesclerócitos com protuberâncias semelhantes a acúleos (espinhos afiados). Este tipo não foi observado entre as esclereídes de plantas atuais que constam na literatura consultada. Dimensões: $96 \mathrm{x}$ $128 \mu \mathrm{m}$ (Figura 2C).

Esclerócito tipo arredondado. Esclerócito de contorno sinuoso. Por possuir contorno externo quadrangular, Bonilla-Barbosa et al. (2000) denominaram este tipo de esclereíde "retangular" ou "subquadrado". Formas com um contorno sinuoso ocorrem tipicamente em superfícies de órgãos vegetais. O contorno parece ter a função de proporcionar um encaixe com as células vizinhas, fazendo com que cada esclereíde funcione como uma peça de quebra-cabeça. Bonilla-Barbosa et al. (2000) observaram formas bem parecidas com esclerócitos do tipo arredondado na cobertura das sementes de algumas espécies de Nymphaea, como por exemplo de Nymphaea ampla L. Isto indica que estes tipos de esclereídes podem desempenhar uma função de proteção nos vegetais. Esclerócitos do tipo arredondado também se assemelham muito com algumas células epidérmicas de plantas. Tucker (1977) reconheceu, em folhas de magnoliáceas, células esclerificadas de epiderme e hipoderme (Figuras 3H-I). Estas células, uma vez fossilizadas, podem aparecer como esclerócitos. Dimensões: 44 x 55 m (Figura 2M); 48 x $55 \mu \mathrm{m}$ (Figura 3K).

Esclerócito tipo caloso. Possui um calo arredondado na parte central de uma das faces. Segundo Tucker (1977), esclereídes com calos semelhantes aos dos esclerócitos tipo caloso ocorrem ao longo da nervura central das lâminas foliares e no pecíolo de algumas magnoliáceas, tais como as espécies Magnolia nitida W.W.Smith e M. omeiensis (Cheng $\& \mathrm{Hu}$ ) Noot (Figura 3A). Convém lembrar que o tipo caloso é 
reconhecido facilmente ao microscópio óptico, quando possui calo maior do que a área central. Caso contrário, consegue-se identificar com a mudança do plano de foco. A Figura 3B mostra a fotomicrografia com foco sobre o calo. Dimensões: 42 x $50 \mu \mathrm{m}$ (Figura 2H); 63 x $70 \mu \mathrm{m}$ (Figura 3B).

Esclerócito tipo compacto. Tem formato de uma estrela com cinco a sete pontas bem reduzidas (Figura 2B). A superfície é lisa e o corpo não possui perfurações. Até o presente momento, não foi possível identificar um tipo exatamente igual entre esclereídes de plantas atuais. Na classificação morfológica proposta por Rao (1949) e Rao \& Buphal (1973), o tipo que se aproxima mais é o "vesiculose sclereid" que possui braços igualmente curtos, mas com extremidades arredondadas. Um caso extremo do tipo compacto, desprovido de projeções, é representado por esclerócitos poligonais que, segundo Tucker (1977), podem ser derivados de hipoderme adaxial esclerificada de algumas magnoliáceas. Dimensões: 47 x $51 \mu \mathrm{m}$ (Figura 2B).

Esclerócito tipo crenulado. Astroesclerócitos com projeções dotadas de leve sinuosidade. A crenulação é observada em diversas esclereídes de famílias atuais, tais como Proteaceae (Torres, 1996) e Theaceae (Curtis et al., 2002; Accardo Filho, 2004). O surgimento da crenulação se deve ao seu crescimento intrusivo e simplástico que, ocorrendo durante a ontogênese das células de esclerênquima, sofre uma deformação em consequência da pressão exercida pelas células de outros tecidos (Scatena \& Scremin-Dias, 2004). O exemplo típico pode ser observado em esclereídes de Camellia japonica $\mathrm{L}$. com projeções que se encontram entremeadas às células de parênquima (Figura 4J). Dimensões: 70 x $90 \mu \mathrm{m}$ (Figura 2E).

Esclerócito tipo cruciforme. Tem forma de cruz. Este tipo pode ser relacionado a estruturas encontradas na hipoderme adaxial esclerificada das lâminas foliares da espécie Magnolia blaoensis (Gagnep) Dandy, família Magnoliaceae, conforme sugerido pelo trabalho de Tucker (1977). Neste caso, o tipo cruciforme seria um caso particular do tipo arredondado com apenas quatro projeções (Figura 3I). Dimensões: 56 x $62 \mu \mathrm{m}$ (Figura 2L).

Esclerócito tipo elongado. Caracteriza-se pelas projeções longas e afiladas que representam mais de $70 \%$ do diâmetro total do esclerócito. As esclereídes atuais que são parecidas com este tipo são ofiuroesclereídes presentes em Proteaceae (Rao \& Buphal, 1973). De fato, pelo julgar das ilustrações de esclereídes do gênero Roupala, apresentadas por Torres (1996), algumas esclereídes de Proteaceae apresentam projeções longas em proporção similar à do tipo elongado. Este, no entanto, difere fundamentalmente por possuir forma de estrela bem desenvolvida. As esclereídes de Roupala têm forma variável e irregular, e, entre as formas apresentadas por Torres (1996), não ocorre nenhuma de contorno estrelado bem formado. Dimensões: 173 x $189 \mu \mathrm{m}$ (exemplar da Figura 2G).

Esclerócito tipo espinhoso. É muito parecido com o

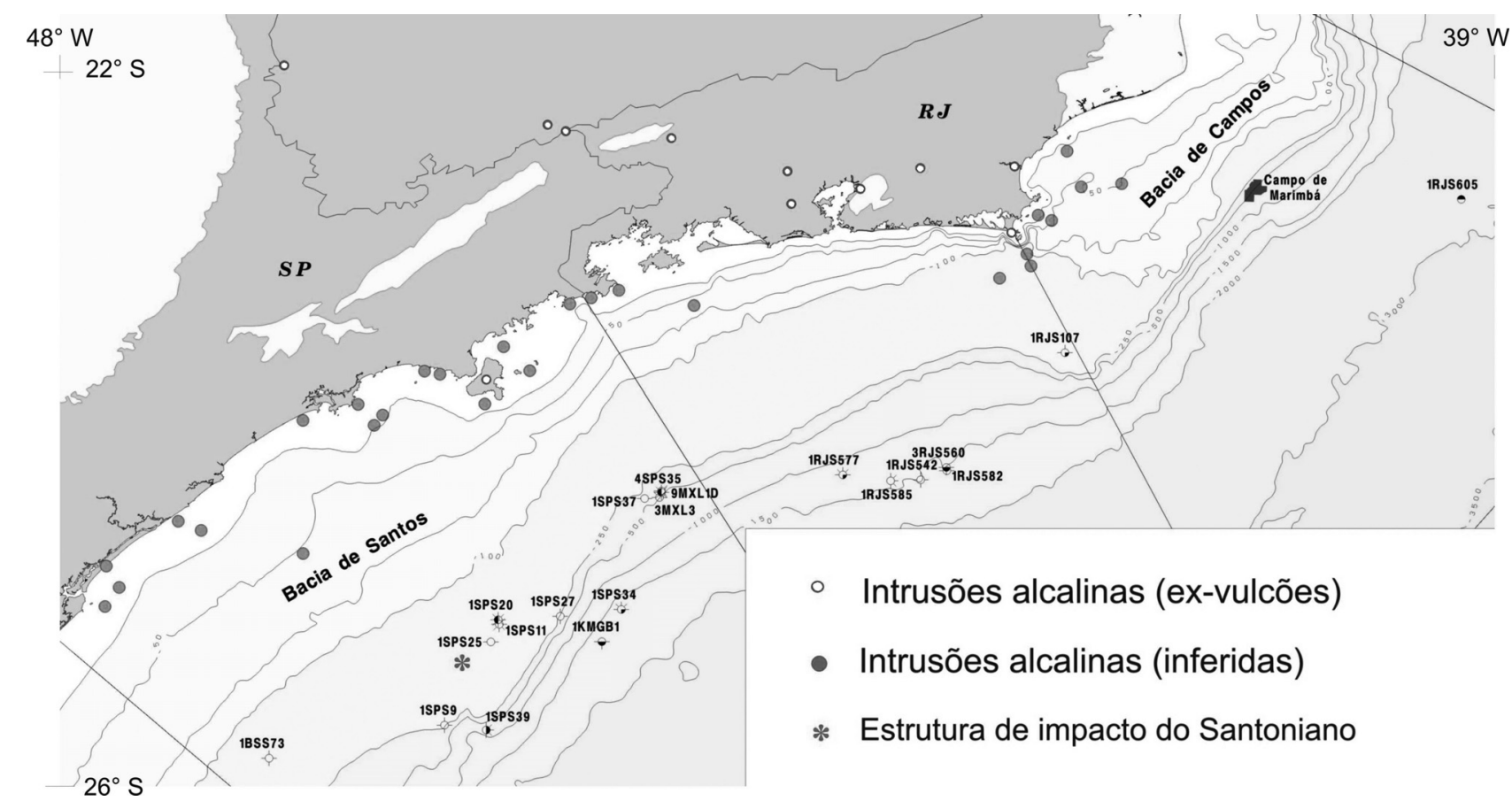

Figura 1. Mapa da área estudada (modificado de Arai, 2008). Poços submarinos com ocorrências de esclerócitos fósseis cretáceos estão indicados por suas respectivas siglas (nomes codificados). Círculos brancos: corpos intrusivos alcalinos na parte emersa, os quais indicariam presença de vulcões incendiários pretéritos. Círculos cinza escuros: corpos alcalinos inferidos a partir de dados geofísicos (Zalán \& Oliveira, 2005). Asterisco: localização da estrutura de impacto do Santoniano (Correia et al., 2005). Abreviaturas: RJ, Rio de Janeiro; SP, São Paulo.

Figure 1. Map of the study area (modified from Arai, 2008). The names of offshore wells with occurrences of Cretaceous fossil sclereids are indicated in black characters (coded names). White circles: onshore alkaline intrusive bodies, which indicate the presence of ancient incendiary volcanoes. Dark gray circles: alkaline bodies inferred by geophysical data (after Zalán \& Oliveira, 2005). Asterisk: site of the structure of the Santonian impact (after Correia et al., 2005). Abbreviations: RJ, Rio de Janeiro; SP, São Paulo. 


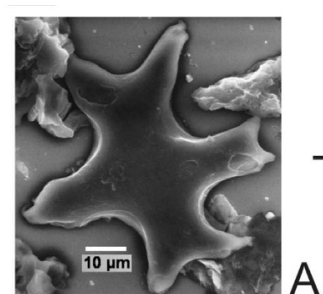

Forma simplex

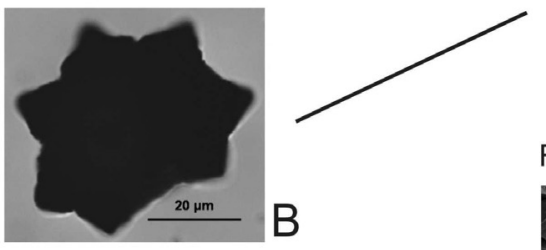

Forma brevis

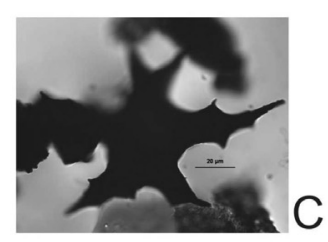

Forma aculeata

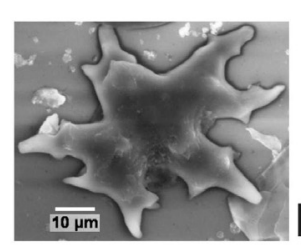

Forma spinosa

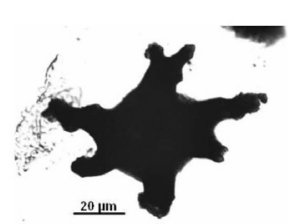

Forma crenulata

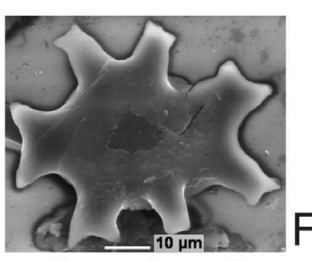

Forma truncata

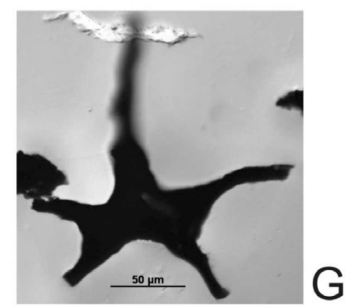

Forma elongata
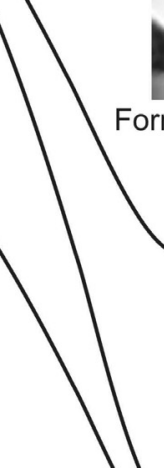

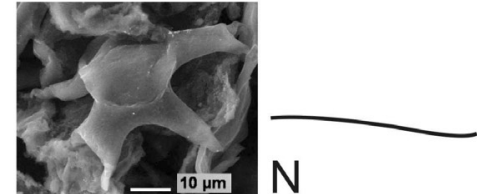

Forma simplex-callosa

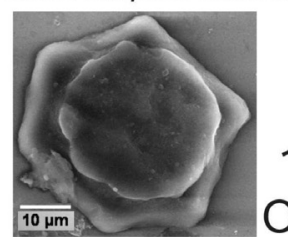

Forma brevis-callosa

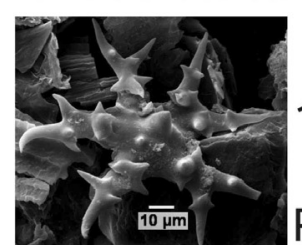

Forma furcata-aculeata

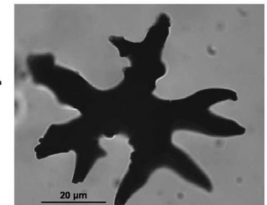

Forma spinosa-furcata
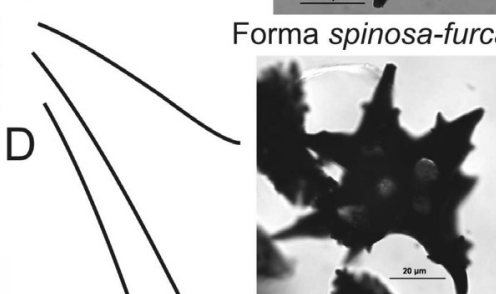

Forma spinosa-perforata

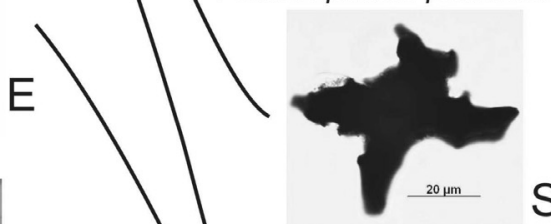

Forma crucis-spinosa
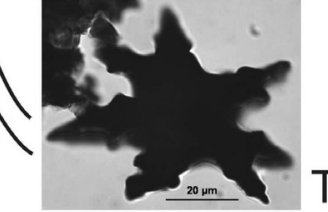

Forma spinosa-crenulata

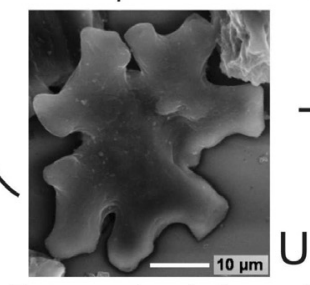

Forma rotunda-truncata

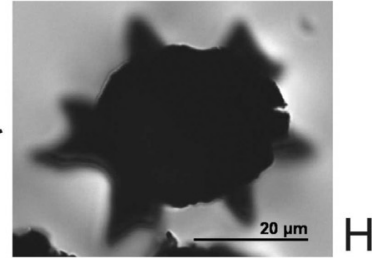

Forma callosa

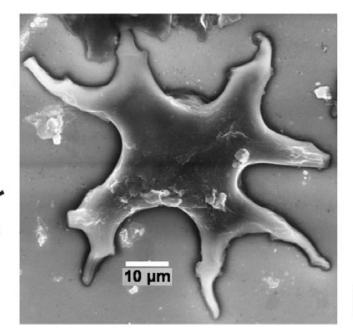

Forma furcata

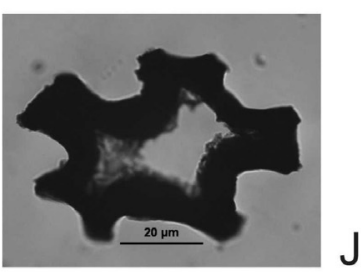

Forma perforata

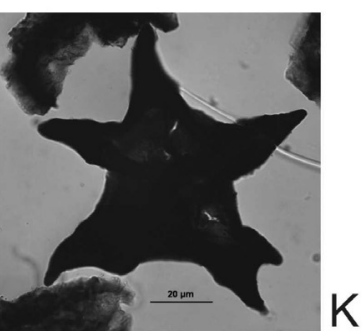

Forma tenuis

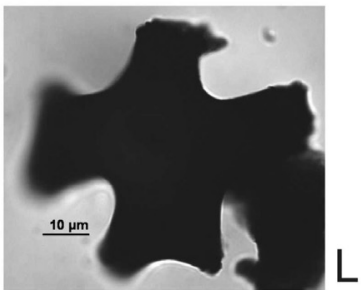

Forma crucis

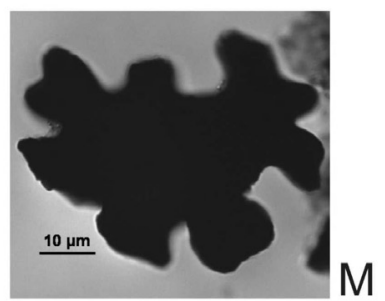

Forma rotunda

Figura 2. Quadro explanatório mostrando os morfotipos básicos e morfotipos combinados de esclerócitos. Todos os exemplares são da bacia de Santos, exceto E, que provém da bacia de Campos.

Figure 2. Classification of basic morphotypes and combined morphotypes of fossil sclereids. All figured specimens are from the Santos Basin, except photo $\mathbf{E}$ (Campos Basin). 
esclerócito tipo aculeado. A diferença é que no tipo espinhoso, as protuberâncias, assim como as extremidades das projeções, são mais arredondadas e não pontiagudas. Atualmente são encontradas esclereídes que são parecidas com estes esclerócitos nas lâminas foliares da espécie Laplacea fruticosa (Schrad.) Kobuski da família Theaceae, conforme a observação de Accardo Filho (2004). De modo semelhante ao tipo crenulado, o espinho pode ser resultado da deformação devida à pressão exercida pelas células vizinhas. Dimensões: 80 x $95 \mu \mathrm{m}$ (Figura 2D); 80 x $87 \mu \mathrm{m}$ (Figura 4K).

Esclerócito tipo perfurado. Possui uma ou mais perfurações na região central do corpo. Estas perfurações são cavidades que acomodavam cristais que foram dissolvidos no processo de maceração da preparação palinológica. De acordo com Kiew \& Ibrahim (1982), alguns esclerócitos deste tipo podem ser relacionados à família Oleaceae, cuja ocorrência típica é observada em folhas da espécie Chionanthus evenius (Stapf)
R. Kiew. As esclereídes de Chionanthus são, no entanto, do tipo braquiesclereíde estrelado. Rao (1957) registrou esclereídes perfuradas em folhas de Memecylon oligoneuron B1. (Melastomataceae), mas elas são polimórficas e irregulares, não apresentando forma de estrela. Astroesclereídes perfurados com contorno estrelado bem desenvolvido, como os esclerócitos do tipo perfurado (Figuras 3E-G), foram encontrados, sobretudo em folhas de Loranthaceae (Rao \& Kelkar, 1951) (Figuras 3C-D). Dimensões: 47 x 68 mm (Figura 2J); 66 × $67 \mu \mathrm{m}$ (Figura 3E).

Esclerócito tipo ramificado. Astroesclerócitos com uma ou mais projeções bifurcadas. Ramificações pouco intensas podem ser observadas em esclereídes foliares de Nymphaeaceae (Figuras 4A-B), mas formas com bifurcações numerosas foram encontradas em folhas de Rutaceae (Foster, 1955), Oleaceae (Kiew \& Ibrahim,1982) e Theaceae (Accardo Filho, 2004) (Figuras 4C-E) e em flores de Loganiaceae (Bendre, 1975). Dimensões: 82 x 97 mm (Figu-

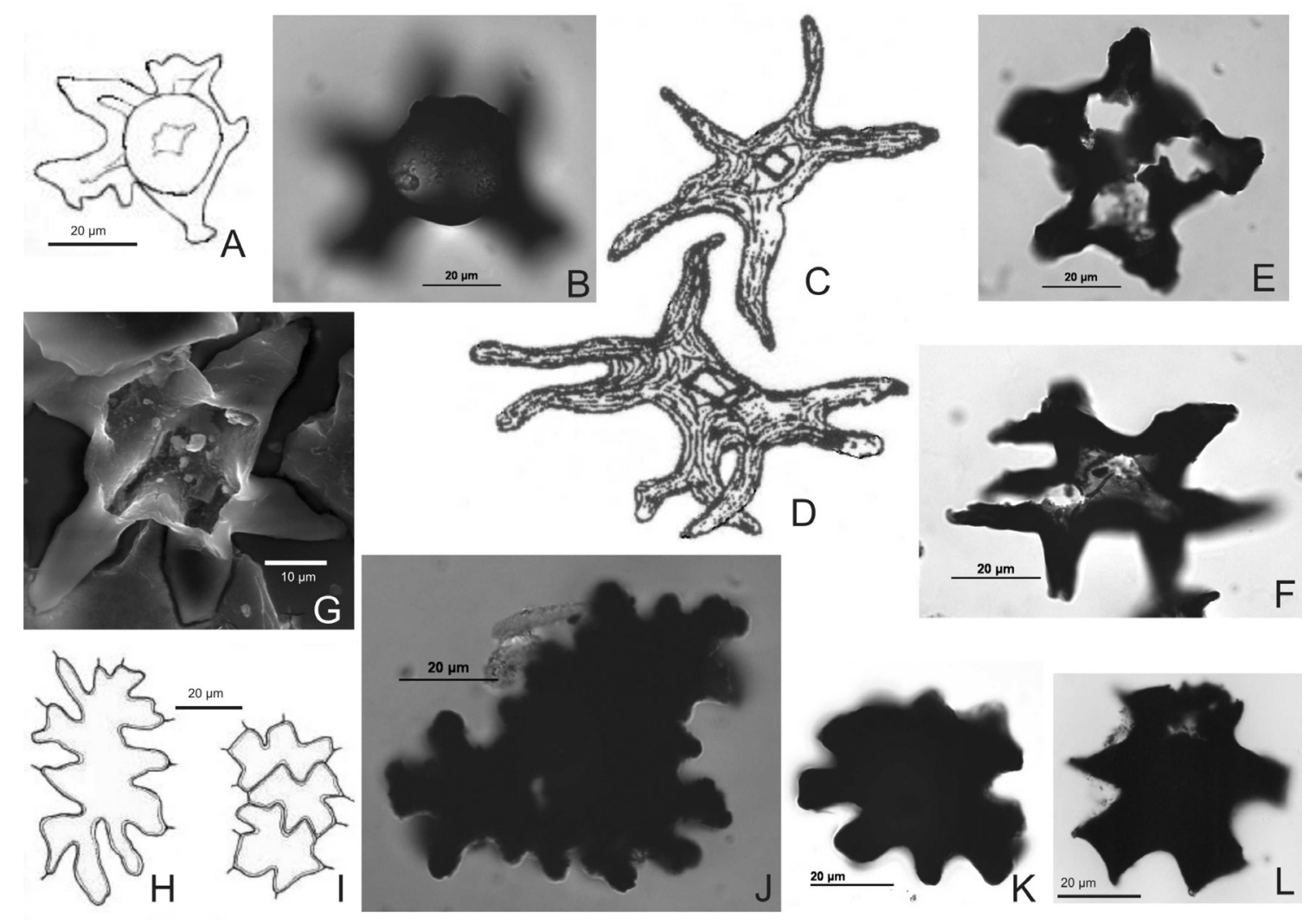

Figura 3. Comparação entre esclereídes de plantas viventes e esclerócitos fósseis. A, astroesclereíde calosa de Magnolia omeiensis (Cheng \& Hu) Noot. (Tucker, 1977); B, astroesclerócito tipo caloso (fotomicrografia com foco sobre o calo); C-D, astroesclereíde perfurada de Loranthus wallichianus Schult. f. ( Rao \& Kelkar, 1951); E-F, astroesclerócito tipo perfurado (fotomicrografias); G, astroesclerócito tipo perfurado (eletromicrografia obtida em microscópio eletrônico de varredura); $\mathbf{H}$, epiderme adaxial esclerificada de Manglietia connifera Dandy; I, hipoderme adaxial esclerificada de Magnolia blaoensis (Gagnep.) Dandy ; J, aglomerado de esclerócitos do tipo arredondado; K, exemplar solitário de esclerócito do tipo arredondado; $\mathbf{L}$, esclerócitos do tipo truncado. Todos os exemplares registrados são da bacia de Santos.

Figure 3. Comparison between the sclereids of extant plants and fossil sclereids: A, thickened, callus-like astrosclereid of Magnolia omeiensis (Cheng \& Hu) Noot. (from Tucker, 1977); B, thickened, callus-like fossil astrosclereid (optical microscopy with focus on the callus); C-D, perforate astrosclereids of Loranthus wallichianus Schult (from Rao \& Kelkar, 1951); E-F, perforate fossil astrosclereids (optical microscopy); G, perforate fossil astrosclereid (scanning electronic microscopy); $\mathbf{H}$, sclerified adaxial epidermis of Manglietia conifera Dandy (from Tucker, 1977); I, sclerified adaxial hypodermis of Magnolia blaoensis (Gagnep.) Dandy (from Tucker, 1977); J, cluster of rounded fossil sclereids; $\mathbf{K}$, solitary specimen of a rounded fossil sclereids; $\mathbf{L}$, truncated fossil sclereid. All fossil specimens are from the Santos Basin. 
ra 2I); 75 x $79 \mu \mathrm{m}$ (Figura 4F); 65 x $70 \mu \mathrm{m}$ (Figura 4H); 70 x 91 $\mu \mathrm{m}$ (Figura 4I).

Esclerócito tipo simples. Astroesclerócito de forma puramente estrelada, despojado de ornamentação e sem ramificação notável (Figura 5). Este tipo de esclereíde é observado principalmente em pecíolos e folhas de Nympheaceae (Gaudet, 1960; Rao \& Banerjee, 1979) e folhas de Gnetaceae (Rao, 1977), ocorrendo menos sistematicamente em folhas de Oleaceae (Kiew \& Ibrahim, 1982) e Theaceae (Herat \& Theobald, 1977). Dimensões: 70 x $75 \mu \mathrm{m}$ (Figura 2A); 67 x 69 $\mu \mathrm{m}$ (Figura 5L); 64 x $79 \mu \mathrm{m}$ (Figura 5M).

Esclerócito tipo tênue. Astroesclerócito com a parte central tênue que chega a ser translúcida ao microscópio óptico. Este tipo não foi observado entre as esclereídes de plantas atuais que constam na literatura consultada. Dimensões: $90 \mathrm{x}$ $95 \mu \mathrm{m}$ (Figura 2K).

Esclerócito tipo truncado. Possui projeções com extremidades truncadas. Existe a possibilidade de este tipo ser célula isolada de aerênquima. Por exemplo, células do aerênquima de Hymenachne (Poaceae), ilustrado por Curtis et al. (2002), caso sejam encontradas isoladas, podem ser identificadas como esclerócitos. Dimensões: 83 x $97 \mu$ m (Figura 2F); 54 x 58 $\mu \mathrm{m}$ (Figura 3L).

Os tipos acima mencionados são básicos e podem se desdobrar em combinações múltiplas de caracteres. Os oito tipos combinados mais comuns são descritos abaixo e podem ser visualizados na coluna central da Figura 2.

Esclerócito tipo arredondado-truncado. É uma forma intermediária, entre o esclerócito tipo arredondado e o truncado, tendo extremidades das projeções truncadas, mas com quinas arredondadas. Este tipo não foi observado entre as esclereídes de plantas atuais que constam na literatura consultada. Dimensões: 44 x $53 \mu \mathrm{m}$ (Figura 2U).

Esclerócito tipo cruciforme-espinhoso. Como o próprio nome diz, tem a forma de cruz, apresentando quatro projeções. Difere do tipo cruciforme típico por possuir extremidades das projeções relativamente pontiagudas, além de apresentar protuberâncias parecidas com espinhos. Diferentemente do esclerócito tipo cruciforme típico, suas projeções se afilam até chegar a suas extremidades. Esclereíde foliar atual pareci-
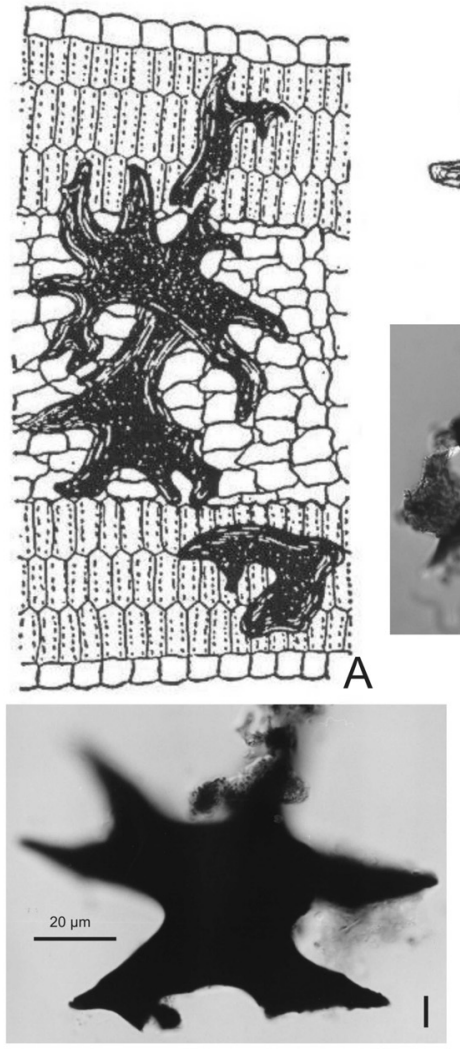
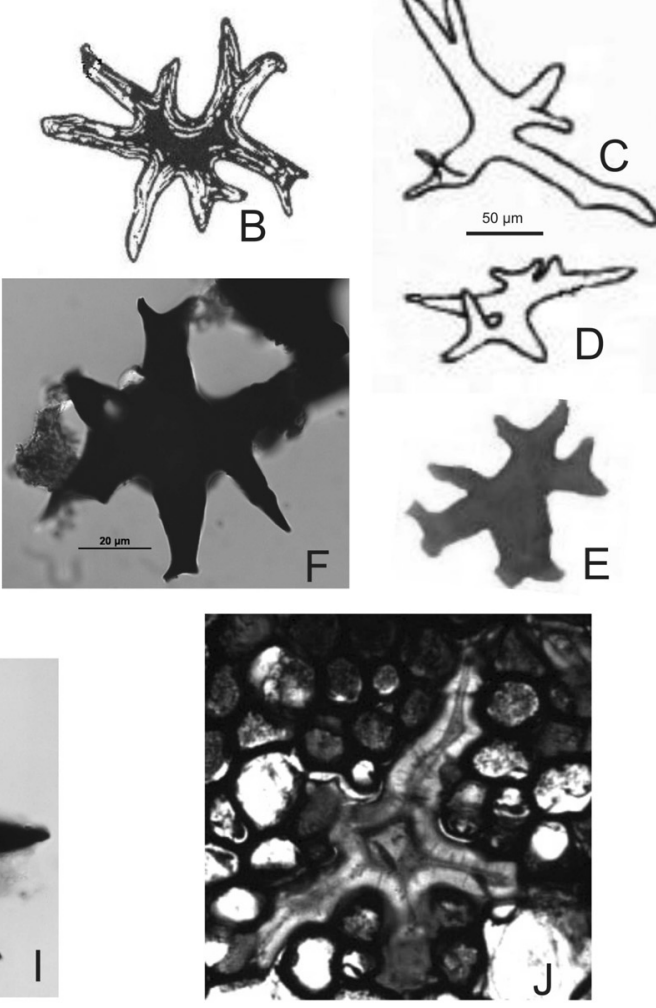
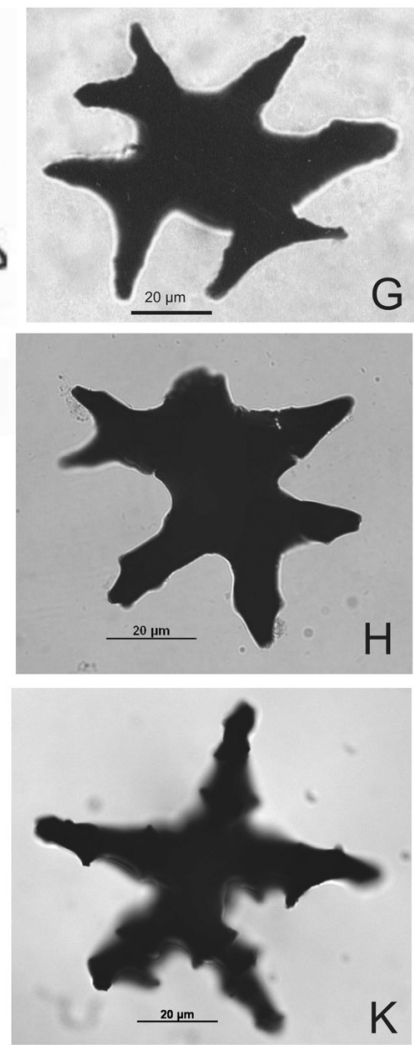

Figura 4. Comparação entre esclereídes de plantas viventes e esclerócitos fósseis. A, astroesclereídes ramificadas de Nuphar japonicum DC. (Rao \& Banerjee, 1979); B, astroesclereíde ramificada de Nuphar orbiculatum (Small) Standley (Rao \& Banerjee, 1979); C-D, astroesclereídes ramificadas de Chionanthus porcatus Kiew (Kiew \& Ibrahim, 1982); E, astroesclereíde foliar ramificada de Camellia japonica L. ( Accardo Filho, 2004); F-I, astroesclerócitos do tipo ramificado; J, astroesclereíde do pecíolo de Camellia sp. (Curtis et al., 2002); K, astroesclerócitos do tipo espinhoso. Todos os esclerócitos fósseis fotografados são da bacia de Santos, exceto G, que provém da Formação São Carlos (bacia do Paraná), e H, que provém da bacia de Campos.

Figure 4. Comparison between the sclereids of extant plants and fossil sclereids: A, branched astrosclereid of Nuphar japonicum DC. (from Rao \& Banerjee, 1979); B, branched astrosclereid of Nuphar orbiculatum (Small) Standley (from Rao \& Banerjee, 1979); C-D, branched astrosclereids of Chionanthus porcatus Kiew (from Kiew \& Ibrahim, 1982); E, branched foliar astrosclereid of Camellia japonica L. (from Accardo Filho, 2004); F-I, branched fossil astrosclereids; J, astrosclereid of petiole of Camellia sp. (from Curtis et al., 2002); K, spiny fossil astrosclereid. All fossil specimens from the Santos Basin, except G (São Carlos Formation, Bauru Group, Paraná Basin) and $\mathrm{H}$ (Campos Basin). 
da com este tipo foi encontrada na espécie Laplacea fruticosa (Schrad.) Kobuski da família Theaceae por Accardo Filho (2004). Dimensões: 53 x $62 \mu \mathrm{m}$ (Figura 2S).

Esclerócito tipo compacto-caloso. Possui a forma de um polígono (geralmente pentágono ou hexágono). No centro deste polígono, existe uma estrutura hemisférica formando um calo. O calo é geralmente menor do que o contorno do esclerócito, de modo que a observação desta estrutura nem sempre é possível ao microscópio óptico. Seu reconhecimento efetivo aconteceu por intermédio da microscopia eletrônica de varredura (Figura 2O). Este tipo não foi observado entre as esclereídes de plantas atuais que constam na literatura consultada. Dimensões: 43 x $50 \mu \mathrm{m}$ (Figura 2O).

Esclerócito tipo espinhoso-crenulado. Possui ao mesmo tempo espinhos e crenulações. Como foi comentado anteriormente, tanto a crenulação como o espinho podem ter a origem no crescimento intrusivo e simplástico que ocorre durante a ontogênese. Como os tipos, espinhoso e crenulado, são associados à Theaceae, espera-se que o tipo espinhosocrenulado também seja relacionado a esta família. Dimensões: 57 x $70 \mu \mathrm{m}$ (Figura 2T).

Esclerócito tipo espinhoso-perfurado. Esclerócito espinho- so e perfurado ao mesmo tempo. Este tipo não foi observado entre as esclereídes de plantas atuais que constam na literatura consultada. Dimensões: 83 x $86 \mu \mathrm{m}$ (Figura 2R).

Esclerócito tipo espinhoso-ramificado. Esclerócito espinhoso e ramificado ao mesmo tempo. Esclereíde foliar atual semelhante a este tipo de esclerócito foi encontrada na espécie Camellia japonica $\mathrm{L}$. da família Theaceae por Accardo Filho (2004). Dimensões: 55 x $70 \mu \mathrm{m}$ (Figura 2Q).

Esclerócito tipo ramificado-aculeado. Esclerócito aculeado e ramificado ao mesmo tempo. Este tipo não foi observado entre as esclereídes de plantas atuais que constam na literatura consultada. Dimensões: 110 x $125 \mu \mathrm{m}$ (Figura 2P).

Esclerócito tipo simples-caloso. Esclerócito simples dotado de um calo central em uma das faces. Como, segundo Tucker (1977), a complexidade das projeções varia muito entre esclereídes foliares da família Magnoliaceae dotadas de calos, admite-se que o tipo simples-caloso possa ser relacionado também à Magnoliacea. Dimensões: 80 x $82 \mu \mathrm{m}$ (Figura 2N).

Além dessas feições, pode-se classificar os esclerócitos de acordo com o número de pontas: variedade tetra (4 pontas), variedade penta (5 pontas), variedade hexa (6 pontas), variedade hepta (7 pontas), e assim por diante.
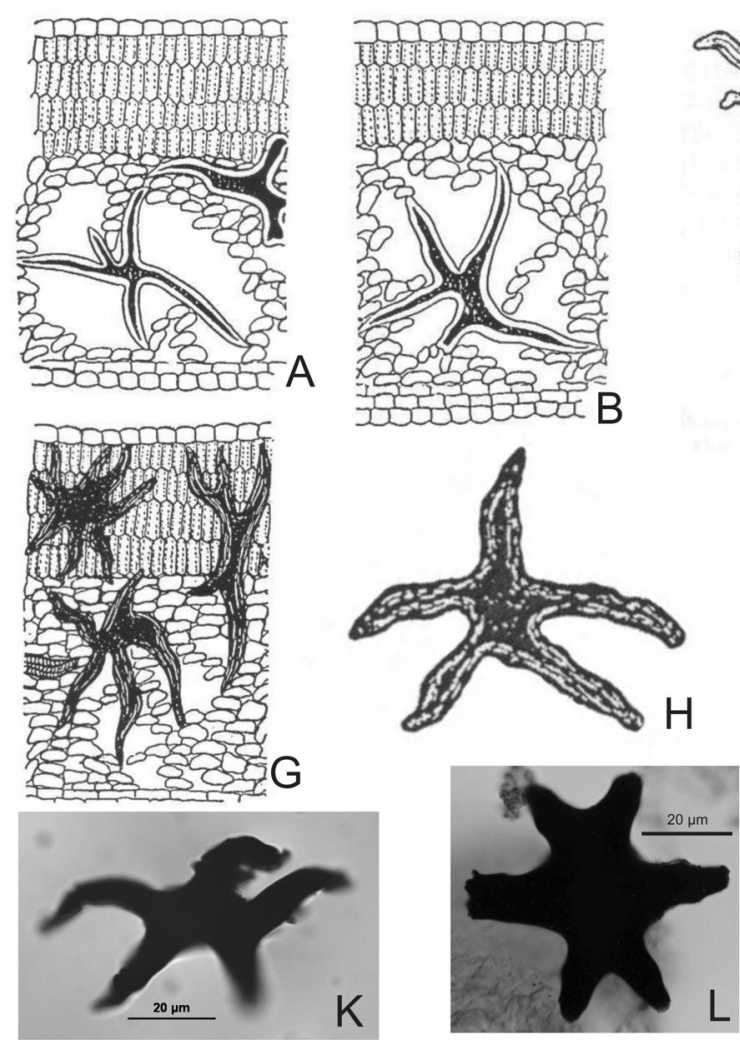
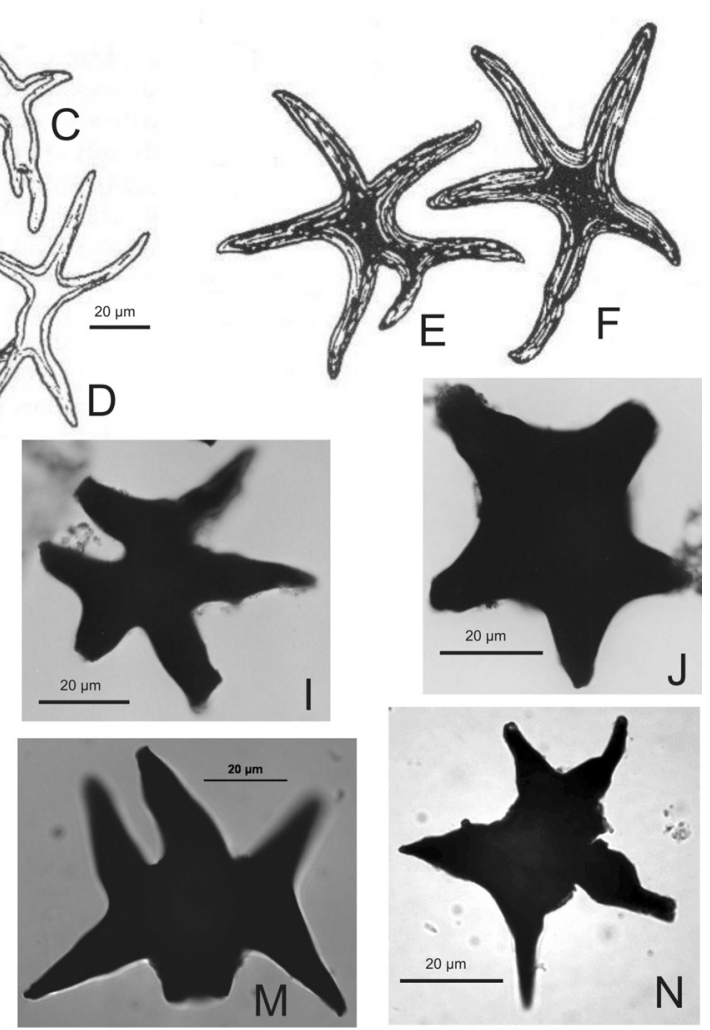

Figura 5. Comparação entre esclereídes de plantas viventes e esclerócitos fósseis. A-B, seção foliar de Nymphaea tetragona Georgi (1775) mostrando astroesclereídes simples in situ (Rao \& Banerjee, 1979); C-D, astroesclereídes simples de Gnetum gnemon L. (Rao, 1977); E-F, astroesclereídes simples de Nuphar orbiculatum (Small) Standley (Rao \& Banerjee, 1979); G, astroesclereídes ramificadas e simples de Nuphar orbiculatum (Small) Standley (Rao \& Banerjee, 1979); H, astroesclereíde típica (Rao \& Bhupal, 1973); I-N, astroesclerócitos fósseis do tipo simples. Todos os exemplares fotografados são da bacia de Santos, exceto J, que provém da bacia de Campos.

Figure 5. Comparison between the sclereids of extant plants and fossil sclereids: A-B, leaf sections of Nymphaea tetragona Georgi showing simple astrosclereids in situ (from Rao \& Banerjee, 1979); C-D, simple astrosclereids of Gnetum gnemon L. (from Rao, 1977); EF, simple astrosclereids of Nuphar orbiculatum (Small) Standley (from Rao \& Banerjee, 1979); G, simple and branched astrosclereids of Nuphar orbiculatum (Small) Standley (figures extracted from Rao \& Banerjee, 1979); H, a typical astrosclereid (from Rao \& Bhupal, 1973); I-N, simple fossil astrosclereids. All fossil specimens are from the Santos Basin, except J (Campos Basin). 


\section{DISCUSSÃO}

\section{Aplicação estratigráfica dos esclerócitos}

Até há pouco tempo, lignina era tida como exclusiva de plantas vasculares, não ocorrendo em briófitas (Kirk \& Farrell, 1987), o que levaria a concluir que estas não possuem esclereídes. Entretanto, Purssel \& Bruggeman-Nannenga (2004), estudando cinco espécies do gênero Fissiden (briófita), encontraram nelas bandas de esclereídes, o que indica que esclereídes estiveram presentes já nas plantas terrestres primordiais. Este fato abre a perspectiva da utilização estratigráfica de esclereídes fósseis desde o Eopaleozóico até o Quaternário. Nos meados do Paleozóico, a ocorrência de esclereídes fósseis já é evidente, sendo exemplos típicos Pseudosporochnus hueberi (Matten) do Devoniano (Stein $\&$ Hueber, 1989) e uma conífera do Permiano (Zhao-Qi Yao et al., 2000). No Mesozóico, é notória a presença de esclerócitos em Araucariaceae (Stockey, 1982; Stockey et al., 1992).

Esclerócitos em forma de " $\mathrm{H}$ " são comuns em algumas famílias de monocotiledôneas (e.g., Araceae e Musaceae), conforme demonstrado em alguns trabalhos (Bloch, 1946; Singh, 1968; Curtis et al., 2002). Devido à forma peculiar, esses esclerócitos seriam facilmente reconhecidos, caso ocorressem no material aqui estudado. Muller (1981), com base no inventário de dados paleopalinológicos, advogou que Musaceae teria surgido somente no final do Neógeno, o que é compatível com a ausência absoluta de esclerócitos em "H" no material do presente trabalho, que é do Cretáceo.

\section{Aplicação paleoecológica dos esclerócitos}

Caso se consiga relacionar morfotipos bem definidos a suas respectivas plantas genitoras, eles podem servir como fósseis-guias de valor paleoambiental, já que, por intermédio deles, poder-se-ia chegar a identificar famílias botânicas. Além disto, estabelecida a relação existente entre a morfologia dos esclereídes e o órgão vegetal onde as mesmas estão presentes, poder-se-ia inferir o tipo de biomassa continental que estava entrando na bacia. Pelo que se observou no presente trabalho, a maioria dos esclerócitos são provenientes de folhas. Isto se explica pelo fato de folhas serem produzidas continuamente e introduzidas em grande quantidade na bacia. Caso se observe um incremento na quantidade de esclerócitos oriundos de órgãos mais permanentes (e.g., caules e raízes), poder-se-ia suspeitar da ocorrência de algum evento catastrófico (e.g., desflorestamento, desabamento, impacto extraterrestre, inundações episódicas, etc.) em terras emersas adjacentes à bacia. A esclerificação de células fora do esclerênquima - por exemplo, a esclerificação de epiderme e/ou hipoderme mencionada por Tucker (1977) pode indicar ambiente hostil que exigiu da planta uma proteção maior. Segundo Mendonça et al. (2007), a presença de esclereídes fósseis seria indicadores da ocorrência de incêndios pretéritos. Esta hipótese decorre do fato de que astroesclereídes fósseis são especialmente abundantes no Santoniano (85,8-83,5 Ma) das bacias de Campos e Santos, onde Arai et al. (2006) reconheceram evidências irrefutáveis de paleoincêndios de grandes proporções. Provavelmente, a lignina, quando submetida a um aquecimento, sem ser consumida, torna-se quimicamente mais estável, aumentando a chance de sua fossilização.

\section{CONCLUSÕES}

Esclerênquima é encontrado desde as briófitas e pteridófitas até as angiospermas, o que possibilitaria potencialmente sua aplicação estratigráfica dentro de uma grande gama de tempo geológico (pelo menos, do Eopaleozóico ao Recente), caso registros de seus fósseis ocorram de modo sistemático.

O levantamento realizado no Cretáceo Superior das bacias do sudeste brasileiro permitiu a identificação de 13 morfotipos básicos (tipos aculeado, arredondado, caloso, compacto, crenulado, cruciforme, espinhoso, longo, perfurado, ramificado, simples, tênue e truncado), além de oito morfotipos combinados. O número de tipos combinados deve crescer com o prosseguimento do estudo.

$\mathrm{Na}$ associação palinológica estudada, os grãos de pólen mais frequentes são do tipo efedróides (ephedroid pollen grains) - Equisetosporites, Gnetaceaepollenites e Steevesipollenites -, o que sugere que os esclerócitos do tipo simples sejam mesmo derivados de gnetófitas, que são também a planta-mãe do pólen efedróide.

O estabelecimento da relação entre morfotipos de esclerócitos e famílias botânicas das plantas genitoras aprimoraria a sua aplicação como ferramentas bioestratigráfica e paleoecológica, mas, mesmo sem essa determinação, o inventário de morfotipos bem caracterizados apontaria para sua utilização como marcadores de bio-horizontes, já que vários deles não têm representação entre as plantas atuais e, portanto, possuem seu nível de extinção em algum ponto do pré-Quaternário, na coluna geológica.

Caso funcionem como fósseis-guias, esclerócitos fósseis serão de grande valia para a execução de palinoestratigrafia nas bacias de Santos e Campos, onde eles são especialmente abundantes em níveis estratigráficos coevos aos paleoincêndios, dentro dos quais a frequência de palinomorfos convencionais (esporos, grãos de pólen, dinoflagelados, acritarcos e outros) é muito baixa.

\section{AGRADECIMENTOS}

Os autores agradecem a todos os colegas do CENPES que, direta ou indiretamente, contribuíram para a realização deste trabalho e gostariam de manifestar gratidão especial à equipe de técnicos do Laboratório de Preparação Palinológica da BPA; a Rogério da Silva Martins da Costa, pelo registro fotográfico ao microscópio eletrônico de varredura; a Elizabeth Pedrão Ferreira, pela revisão da minuta e sugestões decorrentes; a José Ricardo Maizzato, pelos comentários oportunos e proveitosos; a Cecília Cunha Lana, pela leitura 
crítica da minuta; a Oscar Strohschoen Jr. e Sérgio Michelucci Rodrigues, por terem autorizado a publicação do trabalho; a Ricardo Vieira pelo empréstimo de alguns livros utilizados neste trabalho; e a Geoffrey Playford pela revisão do abstract. Contribuição apresentada no XII SBPP (Florianópolis, 02 a 05 de novembro de 2008).

\section{REFERÊNCIAS}

ABL-Academia Brasileira de Letras 1998. Vocabulário Ortográfico da Língua Portuguesa. Brasília, Imprensa Nacional, 795 p.

Accardo Filho, M.A.P. 2004. Theaceae no estado do Rio de Janeiro. Programa de Pós-graduação em Biologia Vegetal, Universidade Federal do Rio de Janeiro, Dissertação de Mestrado, $112 \mathrm{p}$.

Arai, M. 2005. Histórico da palinoestratigrafia marinha no Brasil com ênfase em dinoflagelados cretáceos. Arquivos do Museu Nacional, 63(3):371-384.

Arai, M. 2008. Evidências palinológicas de vulcanismo incendiário no Cretáceo Superior das bacias do sudeste brasileiro. In: SIMPÓSIO DE VULCANISMO E AMBIENTES ASSOCIADOS, 4, 2008. Anais, Foz do Iguaçu, SBG (CDROM).

Arai, M.; Lana, C.C.; Araújo, C.V. \& Menezes, T.R. 2006. O grande incêndio do Santoniano: considerações geológicas e exploratórias. Boletim de Geociências da Petrobras, Rio de Janeiro, 14(1):125-131.

Bendre, A.M. 1975. Floral sclereids in some Loganiaceae. Proceedings of the Indian Academy of Sciences, $\mathbf{8 1 B}(4)$ :174180.

Bloch. R. 1946. Differentiation and pattern in Monstera deliciosa. The idioblastic development of the trichosclereids in the air root. American Journal of Botany, 33:544-551.

Bonilla-Barbosa, J.; Novelo, A.; Orozco, Y.H. \& MárquezGuzmán, J. 2000. Comparative seed morphology of Mexican Nymphaea species. Aquatic Botany, 68:189-204.

Castro, J.C.; Dias-Brito, D.; Arai, M.; Rodrigues, R. \& Musacchio, E.A. 2002. Formação São Carlos: uma nova unidade para o Grupo Bauru (Cretáceo continental do Brasil). In: SIMPÓSIO SOBRE O CRETÁCEO DO BRASIL, 6, 2002. Boletim de Resumos, Rio Claro, UNESP, p. 351-357.

Correia, G.A.; Menezes, J.R.C.; Bueno, G.V. \& Marques, E.J.J. 2005. Identificação de uma estrutura de impacto no Cretáceo Superior da Bacia de Santos em sísmica de reflexão 3D. Boletim de Geociências da Petrobras, 13(1):123-127.

Curtis, J.D.; Lersten, N.R. \& Nowak, M.D. 2002. Photographic atlas of plant anatomy. Disponível em: <http:// botweb.uwsp.edu/anatomy>. Acessado em 06/10/2008.

Esau, K. 1974. Anatomia das plantas com sementes. São Paulo, Edgard Blucher, 293 p.

Ferreira, A.B.H. 1986. Novo dicionário da língua portuguesa. $2^{\mathrm{a}}$ ed., Rio de Janeiro, Nova Fronteira, 1838 p.

Foster, A.S. 1955. Structure and ontogeny of terminal sclereids in Boronia serrulata. American Journal of Botany, 42:551560 .
Gaudet, J. 1960. Ontogeny of the foliar sclereids in Nymphaea odorata. American Journal of Botany, 47:525-532.

Gnauck, P. 2008. A new high resolution field emission SEM with variable pressure capabilities. Disponível em: <http:// www.zeiss.de/C1256E4600307C70/EmbedTitelIntern/ the_new_high_resolution_fesem_with_vp_capabilites/\$File/ $\mathrm{th} \mathrm{e}_{-} \mathrm{n}$ e w $\mathrm{w}_{-} \mathrm{ig} \mathrm{h} \mathrm{r}_{\mathrm{e}} \mathrm{s}$ o l u t i o n_f e sem_with_vp_capabilites.pdf>. Acessado em: 08/10/2008.

Herat, T.R. \& Theobald, W.L. 1977. Comparative studies of vegetative anatomy in the Theaceae of Sri Lanka. Botanical Journal of the Linnean Society, 75:375-386.

Kiew, F.L.S. \& Ibrahim, C.S. 1982. Comparative study of leaf anatomy of Malaysian species of Chionanthus and Olea (Oleaceae) with special reference to foliar sclereids. Botanical Journal of the Linnean Society, 84:79-110.

Kirk,T.K. \& Farrell, R.L. 1987. Enzymatic "combustion": the microbial degradation of lignin. Annual Review of Microbiology, 41:465-505.

Mendonça, J.O.; Mendonça Filho, J.G.; Oliveira, A.D.; Menezes, T.R.; Sant' anna, A.J.; Souza, J.T. \& Brito, D.M. 2007. Fossil record of carbonized sclerenchymatic tissues (sclereids and fibers) in Brazilian sedimentary basins. In: CONGRESSO BRASILEIRO DE PALEONTOLOGIA, 20, 2007. Anais, Búzios, SBP, p. 144.

Müller, J. 1981. Fossil pollen records of extant angiosperms. The Botanical Review, 47(1):1-142.

Pursell, R.A. \& Bruggeman-Nannenga, M.A. 2004. A revision of the infrageneric taxa of Fissidens. The Bryologist, 107(1):1-20.

Rao, A.N. 1977. Morphogenesis of Sclereids in Gnetum gnemon. Annals of Botany, 45(5):1009-1016.

Rao, T.A. 1949. Foliar Sclereids in the Oleaceae-1. Journal of the Indian Botanical Society, 26:251-254.

Rao, T.A. 1951. Studies on foliar sclereids. A preliminary survey. Journal of the Indian Botanical Society, 30:28-39.

Rao, T.A. 1957. Comparative morphology and ontogeny of foliar sclereids in seed plants, I. Memecylon L. Phytomorphology, 7:3068-330.

Rao, T.A. \& Banerjee, B.C. 1979. On foliar sclereids in the Nymphaeaceae sensu lato and their use in familial classification. Proceedings of the Indian Academy of Sciences, 88:413-422.

Rao, T.A. \& Bhupal, O.P. 1973. Typology of Sclereids. Proceedings of the Indian Academy of Sciences, 77:41-55.

Rao, T.A. \& Kelkar, S.S. 1951. Studies on foliar sclereids in Dicotyledons, III. Journal of Bombay University, 20:16-20.

Scatena, V.L. \& Scremin-Dias, E. 2004. Parênquima, Colênquima e Esclerênquima (Capítulo 4). In: B. Appezzato-da-Glória, \& S.M. Carmello-Guerreiro (eds.), Anatomia Vegetal, UFV, p. 109-119.

Singh, H. 1968. Foliar sclereids in some species of Raphidophora and Scindapsusi. The Garden Bulletin, 22:461-464.

Stein, W.E. \& Hueber, F.M. 1989. The Anatomy of Pseudosporochnus: P. hueberi from the Devonian of New York. Review of Palaeobotany and Palynology, 60:311-359.

Stockey, R.A. 1982. The Araucariaceae: an evolutionary perspective. Review of Palaeobotany and Palynology, 37:133-154. 
Stockey, R.A.; Nishida, H. \& Nishida, M. 1992. Upper Cretaceous araucarian cones from Hokkaido: Araucaria nihongii sp. nov. Review of Palaeobotany and Palynology, 72:27-40.

Torres, F. 1996. Anatomía foliar en Proteaceae sudamericanas, con énfasis en las esclereideas. Plantula, 1(2):107-149.

Tschirch, A. 1889. Angewandte pflanzanatomie. Wien, Urban \& Schwarzenberg, p. 301-302.

Tucker, S.C. 1977. Foliar sclereids in the Magnoliaceae. Botanical Journal of the Linnean Society, 75:325-356.
Uesugui, N. 1979. Palinologia: técnicas de tratamento de amostras. Boletim Técnico da Petrobras, 22(4):711-175.

Zalán, P.V. \& Oliveira, J.A.B. 2005. Origem e evolução estrutural do sistema de riftes cenozóicos do sudeste do Brasil. Boletim de Geociências da Petrobras, 13(2):269-300.

Zhao-Qi Yao; Lu-Jun Liu; Rothwell, G.W. \& Mapes, G. 2000. Szecladia new genus, a late Permian conifer with multiveined leaves from south China. Journal of Paleontology, 74(3):524-531.

Received in December, 2008; accepted in February, 2010. 